\title{
Doses, fontes e épocas de aplicação de nitrogênio em trigo irrigado em plantio direto
}

\author{
Marcelo Carvalho Minhoto Teixeira Filho(1), Salatiér Buzetti(1), Marcelo Andreotti(1), Orivaldo Arf(2) \\ e Cleiton Gredson Sabin Benett ${ }^{(3)}$
}

\begin{abstract}
(1)Universidade Estadual Paulista (Unesp), Departamento de Fitossanidade, Engenharia Rural e Solos, Campus de llha Solteira, Caixa Postal 31, CEP 15385-000 Ilha Solteira, SP. E-mail: mcmtf@yahoo.com.br, sbuzetti@agr.feis.unesp.br, dreotti@agr.feis.unesp.br (2)Unesp, Departamento de Fitotecnia, Tecnologia de Alimentos e Socioeconomia. E-mail: arf@agr.feis.unesp.br ${ }^{(3)}$ Universidade Estadual do Mato Grosso do Sul, Unidade de Aquidauana, Rua João Dias, no 640, Bairro Alto, CEP 79200-000 Aquidauana, MS. E-mail: cgbenett@uems.br
\end{abstract}

Resumo - O objetivo deste trabalho foi avaliar os efeitos de doses e fontes de nitrogênio, sobre os componentes de produção e a produtividade de trigo irrigado (Triticum aestivum), aplicados na semeadura ou em cobertura, sob plantio direto. Foram utilizadas fontes com e sem inibidor de nitrificação (Entec), aplicadas ao sulco de semeadura ou em cobertura. O trigo foi cultivado em Selvíria, MS, em região de cerrado de baixa altitude. Utilizou-se o delineamento experimental de blocos ao acaso, com quatro repetições, em esquema fatorial $5 \times 3 \times 2$. Os tratamentos consistiram da combinação de: cinco doses de N, 0,50,100, 150 e $200 \mathrm{~kg} \mathrm{ha}^{-1}$; três fontes, Entec, sulfato de amônio e ureia; e duas épocas de aplicação, na semeadura, ao lado das linhas, ou em cobertura. As fontes de $\mathrm{N}$ tiveram efeito semelhante sobre a altura de plantas e a produtividade de grãos do trigo irrigado. A aplicação total de $\mathrm{N}$ na semeadura e a aplicação tradicional, em semeadura e cobertura, são igualmente viáveis. O incremento das doses de $\mathrm{N}$ até a dose de $121,5 \mathrm{~kg} \mathrm{ha}^{-1}$, em média, aumenta a produtividade de grãos, independentemente da época de aplicação e da fonte de $\mathrm{N}$ utilizada.

Termos para indexação: Triticum aestivum, adubação nitrogenada, cereais de inverno, inibidor de nitrificação, produtividade de grãos, solo de cerrado.

\section{Doses, sources and time of nitrogen application on irrigated wheat under no-tillage}

\begin{abstract}
The objective of this work was to evaluate the effects of different doses and sources of nitrogen, applied at sowing or at side-dressing, on the yied components and grain yield of irrigated wheat, under no-tillage. Nitrogen sources with or without the nitrification inhibitor (Entec) were used for applications at sowing or at side-dressing periods. Wheat was cultivated in Selvíria, state of Mato Grosso do Sul, Brazil in a low-altitude Cerrado region. A randomized block design was used in the factorial arrangement $5 \times 3 \times 2$, with four replicates. Treatments consisted of the combination of: five $\mathrm{N}$ doses, 0, 50, 100, 150 and $200 \mathrm{~kg} \mathrm{ha}^{-1}$; three sources, Entec, ammonium sulfate, and urea; and two application times, at sowing, near of the lines, or at side-dressing. The different $\mathrm{N}$ sources had similar influence on plants height and grain yield of irrigated wheat. Nitrogen applications, totally at sowing and in the traditional way, at sowing and at side-dressing, are both equally viable. The increment of the $\mathrm{N}$ doses up to $121.5 \mathrm{~kg} \mathrm{ha}^{-1}$ increases the grain yield, independently of application time and $\mathrm{N}$ source.
\end{abstract}

Index terms: Triticum aestivum, nitrogen fertilization, winter cereals, nitrification inhibitor, grain yield, savannah soil.

\section{Introdução}

As condições de solo, clima e topografia favoráveis ao cultivo de trigo, tanto de sequeiro quanto irrigado, em épocas e altitudes definidas pela pesquisa, fazem do Brasil Central região de grande potencial para a expansão dessa cultura, com a perspectiva de propiciar, a médio prazo, a autossuficiência na produção nacional.
Além disso, a inserção do trigo no Cerrado contribui para diversificar os sistemas produtivos regionais (Reunião da Comissão Centro Brasileira de Pesquisa de Trigo, 2005).

A utilização de cultivares de trigo, com alto potencial produtivo de grãos, e a adubação nitrogenada são essenciais para a obtenção de alta produtividade. Todavia, a adubação requer cuidados no que concerne

Pesq. agropec. bras., Brasília, v.45, n.8, p.797-804, ago. 2010 
à época e às doses de aplicação. Pequenas doses limitam a produtividade, mas altas doses podem levar ao acamamento, dificultar a colheita e causar queda de produtividade. Além disso, podem trazer prejuízo ao ambiente, pela lixiviação de nitrato para lençóis de água, e prejuízo ao produtor por gasto desnecessário com a compra do adubo nitrogenado.

Tradicionalmente, as culturas anuais recebem, na semeadura, apenas uma fração da dose total do $\mathrm{N}$ de que necessitam, e o restante é aplicado, em cobertura, nas entrelinhas, nos períodos de maior exigência. Isto ocorre em razão de três fatores: baixa exigência inicial, possibilidade de perdas por lavagem e elevado índice salino dos fertilizantes nitrogenados.

Atualmente, a época de aplicação de $\mathrm{N}$ é um dos aspectos mais polêmicos no manejo da adubação nitrogenada de gramíneas em sistema de plantio direto, com sucessão de gramíneas, uma vez que, nos primeiros anos de adoção desse sistema, pode ocorrer a carência inicial de $\mathrm{N}$ decorrente da imobilização causada pela decomposição microbiana dos resíduos da cultura antecessora. Assim, em alguns casos, a antecipação da adubação nitrogenada, em relação às recomendações convencionais ou, até mesmo, em relação à semeadura da cultura, pode ser mais eficiente no aumento da produtividade das culturas graníferas anuais (Kluthcouski et al., 2006). Entretanto, há necessidade de mais estudos, para a cultura do trigo em regiões com inverno seco e irrigação controlada. É fundamental, também, o estudo de diferentes fontes de $\mathrm{N}$, uma vez que esses fertilizantes têm efeito diferente quando aplicados ao solo, em especial no que se refere às perdas.

A ureia é o fertilizante nitrogenado mais utilizado no Brasil, por suas vantagens comparativas em termos de facilidade de fabricação e custo final para o agricultor. Do ponto de vista agronômico, a ureia apresenta uma séria limitação nas aplicações à superfície do solo, em razão das chances de perdas por volatilização de $\mathrm{NH}_{3}$. O sulfato de amônio, no entanto não sofre volatilização de nitrogênio amoniacal $\left(\mathrm{N}-\mathrm{NH}_{3}\right)$, quando o $\mathrm{pH}$ é inferior a 7. Porém, esse fertilizante tem sua eficiência reduzida, basicamente, pela lixiviação de nitratos.

Para maior eficiência dos adubos nitrogenados, foi lançado recentemente o adubo nítrico amoniacal sulfonitrato de amônio (Entec), que possui 26\% de $\mathrm{N}$ total, em sua maior parte na forma amoniacal (18,5\% amoniacal e $7,5 \%$ na forma nítrica) e $12 \%$ de enxofre. O Entec apresenta, em sua composição, moléculas DMPP (3,4 dimetilpirazolfosfato), que atuam na inibição de nitrificação (Los fertilizantes y su uso, 2006). A inibição do processo de nitrificação é interessante pois pode otimizar a adubação nitrogenada, já que mantém o $\mathrm{N}$ na forma de $\mathrm{NH}_{4}^{+}$que, além de mais assimilável e disponível por mais tempo para as plantas, reduz as perdas do $\mathrm{NO}_{3}^{-}$por lixiviação.

Todavia, os estudos sobre a resposta dos componentes de produção e produtividade do trigo à adubação nitrogenada são insuficientes, e é necessário que sejam feitos em condições específicas de ambiente, como a região dos cerrados de baixa altitude, onde há necessidade do uso da irrigação.

O objetivo deste trabalho foi avaliar os efeitos de diferentes doses e fontes de $\mathrm{N}$, aplicados na semeadura ou em cobertura, sobre os componentes de produção e a produtividade do trigo irrigado, sob plantio direto, cultivado em região de cerrado de baixa altitude.

\section{Material e Métodos}

O experimento foi conduzido em 2006 e2007, em área experimental pertencente à Faculdade de Engenharia da Universidade Estadual Paulista, em Selvíria, MS, a $20^{\circ} 22^{\prime} \mathrm{S}, 51^{\circ} 22^{\prime} \mathrm{W}$ e altitude de $335 \mathrm{~m}$. O solo é classificado como Latossolo Vermelho distrófico, de textura argilosa (Santos et al., 2006), com valores de granulometria de 420, 50 e $530 \mathrm{~g} \mathrm{~kg}^{-1}$ de areia, silte e argila, respectivamente. Esse solo foi originalmente ocupado por vegetação de cerrado e é cultivado por culturas anuais há mais de 25 anos. O clima da região é Aw, de acordo com Köppen, definido como tropical úmido, com estação chuvosa no verão e seca no inverno. As médias anuais de temperatura e precipitação pluvial são de $23,5^{\circ} \mathrm{C}$ e $1.370 \mathrm{~mm}$, e a umidade relativa do ar fica entre 70 e $80 \%$. Os valores diários de temperatura média e umidade relativa do ar, bem como os totais diários de precipitação pluvial, durante o período de condução do experimento, estão apresentados na Figura 1.

Os atributos químicos do solo da área experimental, na camada de $0-0,20 \mathrm{~m}$ de profundidade, foram determinados antes da instalação do experimento, segundo metodologia proposta por Raij \& Quaggio (1983), e tiveram os seguintes resultados: $22 \mathrm{mg} \mathrm{dm}^{-3}$ de P (resina); $22 \mathrm{mg} \mathrm{dm}^{-3}$ de S; $27 \mathrm{~g} \mathrm{dm}^{-3}$ de matéria orgânica; 5,9 de pH em $\mathrm{CaCl}_{2} ; 3,3,47,0,16,0$ e 
28,0 $\mathrm{mmol}_{\mathrm{c}} \mathrm{dm}^{-3}$ de $\mathrm{K}, \mathrm{Ca}, \mathrm{Mg}, \mathrm{H}+\mathrm{Al}$, respectivamente e $70 \%$ de saturação por bases.

Utilizou-se o delineamento experimental de blocos ao acaso, com quatro repetições, em esquema fatorial $5 \times 3 \times 2$. Os tratamentos consistiram da combinação de: cinco doses de N, 0, 50, 100, 150 e $200 \mathrm{~kg} \mathrm{ha}^{-1}$; três fontes, Entec, sulfato de amônio e ureia; e duas épocas de aplicação, na semeadura, ao lado das linhas, ou em cobertura nas entrelinhas. As dimensões das parcelas foram de $5 \mathrm{~m}$ de comprimento, com cinco linhas espaçadas de $0,17 \mathrm{~m}$, e 80 sementes por metro, nos dois anos agrícolas. A área útil da parcela, com exclusão das bordaduras, foi de $2,55 \mathrm{~m}^{2}$.

Os tratamentos foram instalados em local onde o sistema plantio direto havia sido implantado há oito anos. Durante o verão, a área foi cultivada com milho, tanto em 2006 quanto em 2007. Antes da semeadura do trigo, a área foi dessecada com o herbicida glifosato (1.500 $\mathrm{g} \mathrm{ha}^{-1}$ do i.a.). As sementes foram tratadas com carboxin + thiram $(60+60 \mathrm{~g}$ i.a.
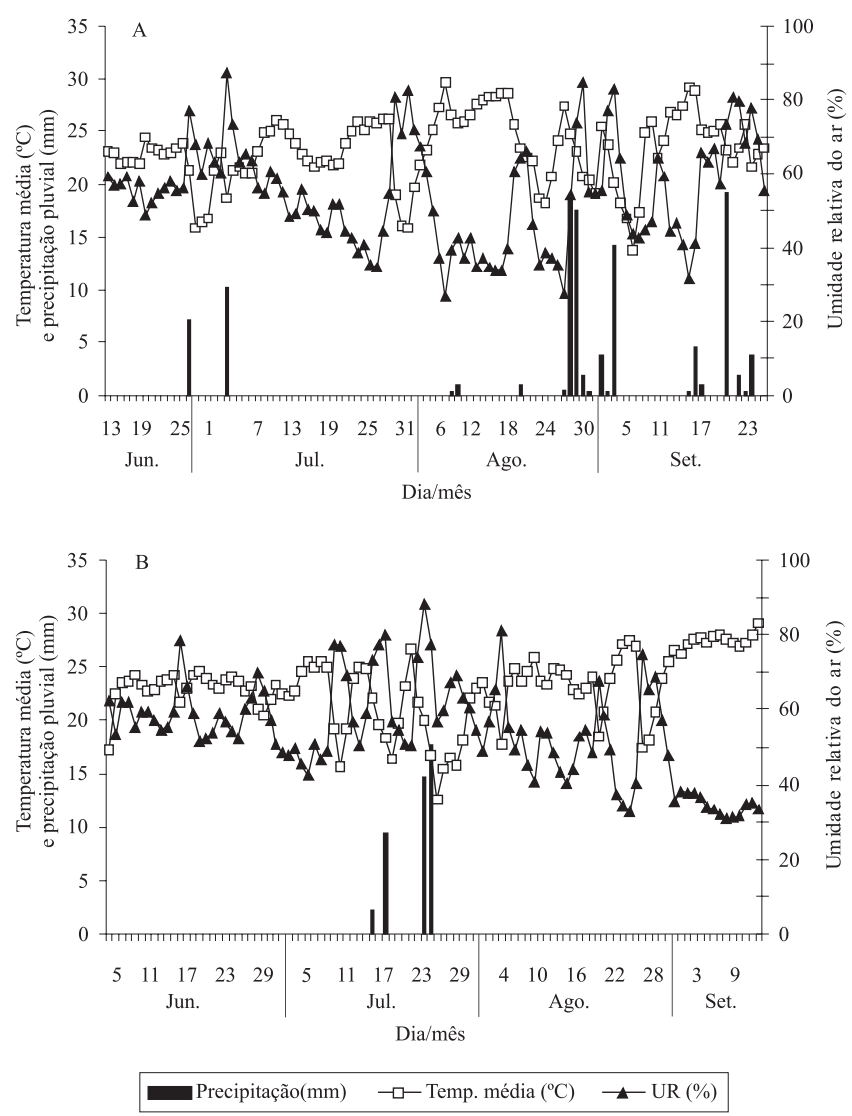

Figura 1. Precipitação pluvial, temperatura média e umidade relativa do ar (UR) diárias, durante a condução do experimento, em 2006 (A) e 2007 (B), em Selvíria, MS.
$100 \mathrm{~kg}^{-1}$ de sementes). A cultivar de trigo utilizada foi a E 21, recomendada para a Região do Cerrado, que tem qualidade panificativa intermediária, e resistência a todas as raças de ferrugem da folha e do colmo verificadas no Brasil. A semeadura foi realizada mecanicamente, nos dias 13 e 5 de junho de 2006 e 2007, respectivamente. Em seguida, a área foi irrigada por aspersão, por meio de pivô central, com lâmina de água de aproximadamente $14 \mathrm{~mm}$, para minimizar as perdas de $\mathrm{N}$ por volatilização da amônia, e para promover a germinação das sementes. As plântulas emergiram cinco dias após a semeadura.

Com base nas características químicas do solo da área experimental, calculou-se a adubação química básica no sulco de semeadura, constante para todos os tratamentos, que foi de: 10,75 e $25 \mathrm{~kg} \mathrm{ha}^{-1} \mathrm{de} \mathrm{N}$, $\mathrm{P}_{2} \mathrm{O}_{5}$ e $\mathrm{K}_{2} \mathrm{O}$, respectivamente, em ambos os anos de cultivo. Para adubação à semeadura, foram aplicados os seguintes fertilizantes: ureia, superfosfato simples e cloreto de potássio. A adubação nitrogenada de cobertura foi realizada nas entrelinhas das parcelas, sem incorporação ao solo, aos 40 dias após a emergência das plantas, no estádio de emborrachamento da cultura. Após essa adubação, a área foi irrigada por aspersão, com uma lâmina de água de aproximadamente $14 \mathrm{~mm}$. Essa operação é comum nos sistemas de produção de grãos irrigados, quando se aplica a ureia.

O manejo de plantas daninhas foi efetuado com a aplicação do herbicida metsulfuron methyl (3,0 $\mathrm{g} \mathrm{ha}^{-1}$ do i.a.), em pós-emergência, em $2006 \mathrm{e}$ 2007. O fornecimento de água foi efetuado de três em três dias ou quando necessário, por meio de um sistema fixo de irrigação por aspersão do tipo pivô central. A colheita do trigo foi realizada manual e individualmente, por unidade experimental, em 2006 e 2007, aos 105 e 100 dias após a emergência das plantas, respectivamente, quando $90 \%$ das espigas apresentavam coloração típica de grãos maduros. O material colhido foi submetido à secagem a pleno sol e foi posteriormente trilhado. Foi feita a abanação manual para a limpeza do material.

Foram realizadas as seguintes avaliações: teor de nitrogênio foliar, analisado na folha bandeira, coletada no início do florescimento da cultura (Cantarella et al., 1997); teor de clorofila, determinado indiretamente no terço médio da folha bandeira de cinco plantas por parcela, no florescimento, por meio de leituras SPAD, 
com auxílio de um clorofilômetro digital CFL 1030 Falker (Falker Automação Agrícola, Porto Alegre, Brasil); altura de plantas na maturação, definida como a distância $(\mathrm{cm})$ do nível do solo até a extremidade das espigas, excluindo-se as aristas; número de espigas por metro na colheita; número total de grãos por espiga por ocasião da colheita, avaliado em dez espigas de trigo por unidade experimental; massa hectolítrica, correspondente à massa de grãos ocupada em um volume de $100 \mathrm{~L}$, determinada em balança de $1 / 4$, com teor de água dos grãos corrigido para 13\% (base úmida); massa de 100 grãos, determinada em balança de precisão de $0,01 \mathrm{~g}$, com teor de água dos grãos corrigido para $13 \%$ (base úmida); produtividade de grãos, determinada pela coleta das plantas contidas nas três linhas centrais de cada parcela. Após a trilhagem mecânica, os grãos foram quantificados, e os dados foram transformados em quilograma por hectare, para $13 \%$ (base úmida).

Os dados foram submetidos à análise de variância, e as médias foram comparadas pelo teste de Tukey, a $5 \%$ de probabilidade, quanto ao efeito das fontes de $\mathrm{N}$ e de épocas de aplicação, e ajustadas as equações de regressão do efeito das doses de N. Para a análise estatística, foi utilizado o programa SISVAR. Procedeu-se, também, às análises de correlação entre o teor de $\mathrm{N}$ e teor de clorofila (leitura SPAD), e entre a produtividade de grãos e todos os componentes de produção, individualmente.

\section{Resultados e Discussão}

Não houve interação significativa entre os fatores doses, fontes e épocas de aplicação de N, em nenhuma das avaliações realizadas.

As fontes de $\mathrm{N}$ Entec e sulfato de amônio proporcionaram maiores teores de $\mathrm{N}$ na folha em relação à ureia, nos dois anos avaliados (Tabela 1). Lourente et al. (2007), ao trabalhar com culturas antecessoras, doses e fontes de $\mathrm{N}$ nos componentes de produção de milho, também verificaram menor incremento no teor foliar de N com aplicação de ureia, em comparação à aplicação de sulfato de amônio. No presente trabalho, no entanto, é interessante observar os altos teores de $\mathrm{N}$ foliar resultantes de todas as fontes, os quais foram

Tabela 1. Teores foliares de $\mathrm{N}$ e de clorofila, altura de plantas, componentes de produção e produtividade de grãos em trigo irrigado, afetados por fontes, épocas de aplicação e doses de $\mathrm{N}^{(1)}$.

\begin{tabular}{|c|c|c|c|c|c|c|c|c|c|c|c|c|c|c|c|}
\hline \multirow[t]{2}{*}{ Tratamento } & \multicolumn{2}{|c|}{$\begin{array}{l}\text { Teor foliar de } \mathrm{N} \\
\qquad\left(\mathrm{g} \mathrm{kg}^{-1}\right)\end{array}$} & \multirow{2}{*}{$\begin{array}{l}\text { Teor de clorofila } \\
\text { (SPAD) } \\
2007\end{array}$} & \multicolumn{2}{|c|}{$\begin{array}{l}\text { Altura } \\
(\mathrm{cm})\end{array}$} & \multicolumn{2}{|c|}{$\begin{array}{l}\text { Espigas } \\
\text { por } \mathrm{m}^{2}\end{array}$} & \multicolumn{2}{|c|}{$\begin{array}{l}\text { Grãos por } \\
\text { espiga }\end{array}$} & \multicolumn{2}{|c|}{$\begin{array}{l}\text { Massa hectolítrica } \\
\left(\mathrm{kg} 100 \mathrm{~L}^{-1}\right)\end{array}$} & \multicolumn{2}{|c|}{$\begin{array}{l}\text { Massa de } 100 \\
\text { grãos }(\mathrm{g})\end{array}$} & \multicolumn{2}{|c|}{$\begin{array}{l}\text { Produtividade } \\
\qquad\left(\mathrm{kg} \mathrm{ha}^{-1}\right)\end{array}$} \\
\hline & 2006 & 2007 & & 2006 & 2007 & 2006 & 2007 & 2006 & 2007 & 2006 & 2007 & 2006 & 2007 & 2006 & 2007 \\
\hline \multicolumn{16}{|l|}{ Fontes } \\
\hline Entec & $47,75 \mathrm{a}$ & $43,56 a$ & $42,03 b$ & $70,47 \mathrm{a}$ & $81,68 \mathrm{a}$ & $291,59 \mathrm{ab}$ & $399,43 a$ & $37,09 a$ & $38,12 \mathrm{ab}$ & $85,97 \mathrm{a}$ & $86,75 \mathrm{ab}$ & $3,90 \mathrm{a}$ & $4,24 \mathrm{a}$ & $3.632 \mathrm{a}$ & $3.535 \mathrm{a}$ \\
\hline SA & $48,35 \mathrm{a}$ & $44,52 \mathrm{a}$ & $43,50 \mathrm{a}$ & $69,27 \mathrm{a}$ & $81,50 \mathrm{a}$ & $303,12 \mathrm{a}$ & $379,77 \mathrm{~b}$ & $37,81 \mathrm{a}$ & $39,11 \mathrm{a}$ & $85,41 \mathrm{a}$ & $86,53 b$ & $3,85 \mathrm{ab}$ & $4,21 \mathrm{a}$ & $3.663 \mathrm{a}$ & $3.585 \mathrm{a}$ \\
\hline Ureia & $45,89 \mathrm{~b}$ & $41,27 \mathrm{~b}$ & $42,02 b$ & $71,17 \mathrm{a}$ & $81,53 \mathrm{a}$ & $286,88 b$ & $393,55 \mathrm{ab}$ & $36,78 \mathrm{a}$ & $37,29 \mathrm{~b}$ & $85,73 a$ & $87,37 \mathrm{a}$ & $3,75 b$ & $4,21 \mathrm{a}$ & $3.676 \mathrm{a}$ & $3.695 \mathrm{a}$ \\
\hline DMS (5\%) & 1,19 & 2,25 & 1,38 & 1,08 & 1,29 & 15,88 & 17,84 & 1,60 & 1,66 & 1,05 & 0,66 & 0,12 & 0,13 & 163 & 161 \\
\hline \multicolumn{16}{|l|}{ Épocas } \\
\hline Semeadura & $44,11 \mathrm{~b}$ & $42,97 \mathrm{a}$ & $41,47 b$ & $70,47 \mathrm{a}$ & $82,05 \mathrm{a}$ & $287,29 b$ & $390,15 \mathrm{a}$ & $37,57 \mathrm{a}$ & $38,40 \mathrm{a}$ & $85,97 \mathrm{a}$ & $86,93 a$ & $3,92 \mathrm{a}$ & $4,18 \mathrm{a}$ & $3.639 \mathrm{a}$ & $3.544 b$ \\
\hline Cobertura & $50,55 \mathrm{a}$ & $43,25 \mathrm{a}$ & $43,56 \mathrm{a}$ & $70,13 \mathrm{a}$ & $81,08 \mathrm{~b}$ & $303,94 a$ & $391,68 \mathrm{a}$ & $36,89 \mathrm{a}$ & $37,55 \mathrm{a}$ & $85,44 \mathrm{a}$ & $86,84 \mathrm{a}$ & $3,75 b$ & $4,25 \mathrm{a}$ & $3.675 \mathrm{a}$ & $3.666 \mathrm{a}$ \\
\hline DMS (5\%) & 0,81 & 2,16 & 0,94 & 0,74 & & 10,88 & 12,10 & 1,10 & 1,13 & 0,42 & 0,45 & 0,08 & 0,09 & 111 & 109 \\
\hline \multicolumn{16}{|c|}{ Doses $\left(\mathrm{kg} \mathrm{ha}^{-1}\right)^{(2)}$} \\
\hline 0 & 42,90 & 33,36 & 34,08 & 69,67 & 81,00 & 297,00 & 353,17 & 37,81 & 36,88 & 85,91 & 88,13 & 3,86 & 4,52 & 3.071 & 2.516 \\
\hline 50 & 47,62 & 42,19 & 42,53 & 69,50 & 81,45 & 305,23 & 411,75 & 37,87 & 39,68 & 85,24 & 87,53 & 3,76 & 4,19 & 3.768 & 4.071 \\
\hline 100 & 47,62 & 45,30 & 45,08 & 70,94 & 81,54 & 288,23 & 401,50 & 37,34 & 39,31 & 85,33 & 87,24 & 3,72 & 4,15 & 3.847 & 3.985 \\
\hline 150 & 48,74 & 47,23 & 45,41 & 71,17 & 82,04 & 286,94 & 404,54 & 35,26 & 39,39 & 86,37 & 86,05 & 3,92 & 4,15 & 3.703 & 3.762 \\
\hline 200 & 49,79 & 47,47 & 45,48 & 70,22 & 81,79 & 292,17 & 383,63 & 37,87 & 38,86 & 85,66 & 85,46 & 3,92 & 4,07 & 3.651 & 3.692 \\
\hline Média & 47,33 & 43,11 & 42,52 & 70,30 & 81,57 & 293,86 & 390,92 & 37,23 & 38,17 & 85,70 & 86,88 & 3,84 & 4,22 & 3.657 & 3.605 \\
\hline CV (\%) & 6,93 & 9,20 & 6,06 & 4,99 & 4,23 & 19,59 & 12,24 & 13,57 & 9,76 & 4,17 & 2,05 & 10,41 & 7,06 & 15,18 & 11,81 \\
\hline
\end{tabular}

${ }^{(1)}$ Médias seguidas de letras iguais, nas colunas, não diferem entre si pelo teste de Tukey, a 5\% de probabilidade. ${ }^{(2)}$ Equações de regressão para: teor foliar de $\mathrm{N}$, em 2006, $\mathrm{y}=44,3520+0,0298 \mathrm{x}\left(\mathrm{R}^{2}=0,80\right)$, e 2007, $\mathrm{y}=33,8344+0,1716 \mathrm{x}-0,00053 \mathrm{x}^{2}\left(\mathrm{R}^{2}=0,99\right)$; teor de clorofila, $\mathrm{y}=34,6733+0,1597 \mathrm{x}-0,00054 \mathrm{x}^{2}$ $\left(R^{2}=0,97\right)$; espigas $m^{-2}$ em 2007, $y=359,3595+0,9400 x-0,00416 x^{2}\left(R^{2}=0,82\right)$; massa hectolítrica em 2007, $y=88,2519-0,0137 x\left(R^{2}=0,96\right) ;$ massa de 100 grãos em 2007, $y=4,4031-0,0019 x\left(R^{2}=0,73\right)$; produtividade de grãos em 2006, $y=3143,3429+12,0262 x-0,0492 x^{2}\left(R^{2}=0,87\right), e$ em 2007, $\mathrm{y}=2712,4810+23,4518 \mathrm{x}-0,0968 \mathrm{x}^{2}\left(\mathrm{R}^{2}=0,78\right)$. 
muito superiores aos da faixa adequada (20-34 $\left.\mathrm{g} \mathrm{kg}^{-1}\right)$, descrita por Cantarella et al. (1997).

No que se refere às épocas de aplicação de $\mathrm{N}$, observa-se que a aplicação em cobertura proporcionou maior teor foliar do que a aplicação na semeadura, em 2006 (Tabela 1). A maior proximidade da aplicação em cobertura do florescimento da cultura, período de coleta das folhas bandeiras para análise do teor foliar de N, pode ser uma das razões para este resultado. Contudo, no ano de 2007 os teores não diferiram estatisticamente entre as épocas de aplicação de N. De acordo com Peruzzo et al. (1994), que estudaram 18 fontes de $\mathrm{N}$ na cultura do trigo, maior absorção de $\mathrm{N}$ ocorre quando elas são aplicadas na semeadura e em cobertura, do que quando aplicadas somente na semeadura.

As doses de $\mathrm{N}$ influenciaram o teor foliar de $\mathrm{N}$ linearmente em 2006 e de forma quadrática em 2007, com ponto de máximo teor estimado com a aplicação de $163 \mathrm{~kg} \mathrm{ha}^{-1}$ de $\mathrm{N}$. Esse aumento da concentração de $\mathrm{N}$ total na folha bandeira, em consequência das doses de $\mathrm{N}$, assemelha-se ao resultado relatado com a cultivar Avante, em que a resposta também foi quadrática, com ponto de máxima estimado em $180 \mathrm{~kg} \mathrm{ha}^{-1}$ de $\mathrm{N}$ (Penckowski, 2006).

Com relação à leitura do clorofilômetro (SPAD), realizada apenas em 2007, que teve como objetivo verificar a absorção e o consumo de luxo de $\mathrm{N}$ das plantas de trigo, constatou-se diferença significativa entre as fontes de $\mathrm{N}$, com o maior teor sendo observado com uso do sulfato de amônio. As épocas de aplicação também tiveram efeito significativo sobre a leitura SPAD, com a aplicação do $\mathrm{N}$ em cobertura tendo proporcionado maior teor de clorofila (SPAD) nas folhas, em comparação à aplicação de $\mathrm{N}$ totalmente em semeadura. As doses de $\mathrm{N}$ influenciaram o teor de clorofila na folha de forma quadrática, com o ponto de máxima leitura igual a $46 \mathrm{SPAD}$, atingido com a estimativa de aplicação de $147 \mathrm{~kg} \mathrm{ha}^{-1}$ de N. O aumento nos valores do índice SPAD, em consequência das doses de $\mathrm{N}$, assemelha-se aos relatados para trigo de inverno submetido às doses $0,50,100,150$, 200, 250 e $300 \mathrm{~kg} \mathrm{ha}^{-1}$ (Lopez-Bellido et al., 2004). Esse comportamento é resultante do aumento da concentração de clorofila, promovido pela maior disponibilidade de $\mathrm{N}$ total nos tecidos. Essa relação é atribuída principalmente ao fato de que 50 a $70 \%$ do $\mathrm{N}$ total da folha é integrante de enzimas que estão associadas aos cloroplastos (Chapman \& Barreto, 1997).

Houve ajuste entre a leitura SPAD e o teor foliar de $\mathrm{N}$ : $\mathrm{y}=1,0222 \mathrm{x}-0,3501\left(\mathrm{R}^{2}=0,69\right)$, em que $\mathrm{x}$ é a leitura SPAD e y o teor foliar de nitrogênio. A correlação entre os teores de $\mathrm{N}$ e de clorofila da folha foi positiva e significativa $\left(\mathrm{r}=0,83^{* *}\right)$. Follett et al. (1992) estudaram o uso do medidor de clorofila para avaliar os teores de $\mathrm{N}$ na planta de trigo de sequeiro, e também constataram associação positiva entre leituras do medidor de clorofila e a concentração foliar de nitrogênio.

As leituras em clorofilômetro aumentaram até a aplicação de $147 \mathrm{~kg} \mathrm{ha}^{-1}$ de N, mas a produtividade de grãos aumentou somente até a dose de $121 \mathrm{~kg} \mathrm{ha}^{-1}$ (2007). Dessa forma, deve-se optar por avaliar a quantidade de $\mathrm{N}$ a ser aplicada em cobertura, considerando-se o incremento nas leituras até a aplicação de $121 \mathrm{~kg} \mathrm{ha}^{-1}$.

Tanto em 2006 quanto em 2007, não houve diferença significativa entre as fontes de $\mathrm{N}$ quanto à altura de planta (Tabela 1). Semelhantemente, Yano et al. (2005) não encontraram diferença significativa entre fontes de N (ureia, sulfato de amônio e nitrato de amônio), quanto à altura de plantas de trigo. As doses de $\mathrm{N}$ também não influenciaram a altura de plantas de trigo em nenhum dos cultivos. Esses resultados contrastam com os de Zagonel et al. (2002), que verificaram que com o aumento da dose de $\mathrm{N}$ ocorre aumento da altura de plantas de trigo. Ao contrário dos resultados com fontes e doses de $\mathrm{N}$, verificou-se diferença significativa na altura das plantas com a aplicação do $\mathrm{N}$ totalmente em semeadura em comparação com a aplicação em cobertura, em 2007, sendo que a antecipação da adubação nitrogenada elevou a estatura das plantas. No entanto, não foi constatado acamamento de plantas, mesmo nas maiores doses de N. Silva (1991) estudou cinco doses de $\mathrm{N}$ e seis cultivares de trigo e também constatou ausência de efeito das doses de $\mathrm{N}$ sobre o acamamento de plantas.

Com relação às fontes de $\mathrm{N}$, houve diferença significativa no número de espigas de trigo por metro quadrado, em ambos os anos de cultivo, e o sulfato de amônio e o Entec proporcionaram mais espigas por metro quadrado, em 2006 (Tabela 1). Em 2007, o Entec e a ureia foram as fontes que apresentaram melhor desempenho. Quanto às épocas de aplicação do $\mathrm{N}$, não houve diferença significativa para esse componente da produção em 2007; porém, em 2006, 
a aplicação do $\mathrm{N}$ em cobertura foi significativamente superior. As doses de $\mathrm{N}$ influenciaram positivamente a quantidade de espigas por metro quadrado em 2007, que, ajustada a uma função quadrática, teve o seu máximo alcançado com a estimativa de $113 \mathrm{~kg} \mathrm{ha}^{-1}$ de N. Zagonel et al. (2002) e Teixeira Filho et al. (2007) também verificaram efeito significativo do aumento das doses de N, aplicadas em cobertura, na forma de ureia, no número de espigas de trigo por metro quadrado. Segundo Sangoi et al. (2007), em alta densidade, esse componente de produção é o mais importante na determinação da produtividade do trigo.

$\mathrm{O}$ número de grãos por espiga foi influenciado significativamente pelas fontes de $\mathrm{N}$, em 2007, e o sulfato de amônio foi a fonte que proporcionou os maiores valores (Tabela 1). Não houve diferença significativa nesse componente da produção entre as épocas de aplicação de $\mathrm{N}$, nos dois anos de cultivo. As doses de $\mathrm{N}$ também não influenciaram significativamente esse componente. Semelhantemente, Silva (1991), ao estudar doses de N e cultivares de trigo, constatou que não houve efeito das doses sobre o número de grãos por espiga. Teixeira Filho et al. (2008) também não verificaram efeito das doses de N, aplicadas em cobertura, em duas populações de plantas e em duas cultivares de trigo irrigado, na Região do Cerrado. No entanto, Coelho et al. (1998) observaram incremento no número de grãos por espiga da cultivar E 22, proporcionado pelo aumento das doses de $\mathrm{N}$.

A massa hectolítrica foi influenciada significativamente pelas fontes de N, em 2007 (Tabela 1), sendo que a ureia proporcionou maior massa hectolítrica que o sulfato de amônio, mas não diferiu estatisticamente do Entec. A aplicação do $\mathrm{N}$ totalmente na semeadura não diferiu significativamente da aplicação em cobertura, nos dois anos de estudo. Entretanto, ressalta-se que, apesar das altas médias de massa hectolítrica obtidas no experimento( $\left.>78 \mathrm{~kg} 100 \mathrm{~L}^{-1}\right)$, que classificam (isoladamente) o trigo como tipo 1, em 2006 foram observadas massas hectolítricas inferiores. Isso pode ser explicado pela ocorrência diferencial de chuvas no final do ciclo da cultura, nos dois anos (Figura 1). Segundo Furlani et al. (2002), uma chuva sobre a lavoura madura reduz a massa hectolítrica e, consequentemente, afeta a qualidade de grãos. Constatou-se comportamento linear decrescente da massa hectolítrica, em consequência do aumento das doses de N, em 2007. Da mesma forma, Trindade et al. (2006), ao testar doses de ureia, encontraram valores de massa hectolítrica decrescentes, quando aumentaram a dose de $\mathrm{N}$ de 0 a $200 \mathrm{~kg} \mathrm{ha}^{-1}$.

A massa de 100 grãos foi significativamente influenciada pelas fontes de $\mathrm{N}$ em 2006, e o Entec proporcionou os maiores valores, apesar de não ter diferido estatisticamente do sulfato de amônio (Tabela 1). Nesse ano, esse componente de produção apresentou maiores valores com a aplicação total do N na semeadura. Segundo Frank \& Bauer (1996), no período compreendido entre a fase de emergência das plântulas e a diferenciação do primórdio floral, a falta de $\mathrm{N}$ reduz a massa de 1.000 grãos. As doses de $\mathrm{N}$ influenciaram a massa de 100 grãos de forma negativa e linear, em 2007. Essa redução nos valores de massa de 100 grãos pela elevação das doses de $\mathrm{N}$ pode ser atribuída ao aumento no número de grãos por espiga, que teriam aumentado a competição por nutrientes e fotoassimilados dentro da espiga e, como consequência, reduzido a massa unitária dos grãos. Entretanto, o mesmo não ocorreu em 2006. As respostas da massa de 100 ou 1.000 grãos à adubação nitrogenada, descritas na literatura, são muito variáveis. Zagonel et al. (2002) verificaram que a adubação nitrogenada não influencia a massa de 1.000 grãos. Por sua vez, Coelho et al. (1998) verificaram aumento na massa de 1.000 grãos até a aplicação de 30-37,2 $\mathrm{kg} \mathrm{ha}^{-1}$ de $\mathrm{N}$, em duas safras avaliadas, com diminuição nesse componente de aplicação de doses superiores. Teixeira Filho et al. (2007) obtiveram aumento da massa de 100 grãos até $68 \mathrm{~kg} \mathrm{ha}^{-1}$ de $\mathrm{N}$, aplicados em cobertura na forma de ureia. De acordo com Okuyama et al. (2004), a massa de grãos é mais importante para a determinação da produtividade de grãos, em condições que resultam em baixo número de colmos por metro quadrado.

Não houve diferença entre as fontes de $\mathrm{N}$ quanto à produtividade de grãos de trigo, em 2006 e 2007 (Tabela 1). Essa ausência de resposta às fontes de $\mathrm{N}$ ocorreu, provavelmente, pelo fato de, logo após sua aplicação, ter sido efetuada a irrigação no experimento, o que teria reduzido as perdas por volatilização, principalmente na forma de $\mathrm{NH}_{3}$ proveniente da ureia. As fontes de $\mathrm{N}$ também podem ter apresentado comportamento semelhante em consequência da baixa precipitação registrada no período de cultivo, já que o experimento foi conduzido na estação seca, o que teria causado menor perda de $\mathrm{N}$ por lixiviação. Comparações 
entre diversos fertilizantes nitrogenados foram feitas por vários autores e, em geral, em condições satisfatórias de umidade do solo, não têm sido encontradas diferenças na eficiência dessas fontes para a produtividade de grãos de trigo, no Cerrado. Megda et al. (2009) avaliaram as fontes sulfonitrato de amônio, sulfato de amônio e ureia, e Silva et al. (2008), a ureia e o Entec em sistema plantio direto. Nenhum desses autores observou efeito das fontes sobre a produtividade.

Em 2007, verificou-se que a aplicação de $\mathrm{N}$ em cobertura proporcionou maior produtividade de grãos; porém, em 2006, a antecipação da adubação nitrogenada não diferiu significativamente da aplicação de $\mathrm{N}$ em cobertura (Tabela 1). Isto ocorreu, provavelmente, porque o solo onde o experimento foi conduzido apresenta boa fertilidade e drenagem, é bastante argiloso e tem bom teor de matéria orgânica. Além disso, o trigo foi cultivado em período de seca, com pouca chuva, o que teria aumentado a eficácia da prática da aplicação antecipada do nutriente. Também Ros et al. (2003), ao testar diferentes métodos de adubação nitrogenada, em plantio direto, e avaliar a disponibilidade de $\mathrm{N}$, verificaram que a aplicação de $\mathrm{N}$ totalmente na semeadura ou em cobertura não diferem no que se refere à produtividade de grãos de trigo.

As doses de $\mathrm{N}$ influenciaram a produtividade de grãos de trigo, em 2006 e 2007, e se ajustaram às funções quadráticas, com a máxima produtividade alcançada, respectivamente, com as estimativas de 122 e $121 \mathrm{~kg} \mathrm{ha}^{-1}$ de N. Bredemeier \& Mundstock (2001), Zagonel et al. (2002), Trindade et al. (2006), Teixeira Filho et al. (2007, 2008) e Povh et al. (2008) também verificaram efeito de $\mathrm{N}$ sobre a produtividade da cultura. No entanto, Pottker et al. (1984), em razão das condições climáticas adversas com a ocorrência de altas precipitações pluviais alternadas com períodos de seca, não verificaram efeito de doses de $\mathrm{N}$ na produtividade dessa cultura.

A produtividade de grãos correlacionou-se de forma positiva com: o teor foliar de N, em $2006\left(0,44^{* *}\right)$ e $2007(0,72 * *)$; o teor de clorofila (leitura SPAD) da folha, em $2007\left(0,76^{* *}\right)$; e com o número de espigas por metro quadrado, em $2007\left(0,74^{* *}\right)$. Piekielek \& Fox (1992) também constataram que o teor de clorofila da folha correlaciona-se positivamente com a produtividade das culturas. As produtividades obtidas (Tabela 1) podem ser consideradas boas para essa região tropical e de baixa altitude, e mostram que a cultura do trigo irrigado pode constituir uma alternativa para rotação de culturas de inverno no Cerrado.

\section{Conclusões}

1. As fontes de nitrogênio Entec, sulfato de amônio e ureia têm efeito similar sobre altura de plantas e produtividade de grãos de trigo, em cultivo irrigado.

2. A aplicação da adubação nitrogenada totalmente por ocasião da semeadura é viável, assim como o fracionamento da aplicação tradicional em semeadura e cobertura, para a cultura do trigo irrigado.

3. As doses de nitrogênio influenciam positivamente os teores de $\mathrm{N}$ foliar e de clorofila, e podem aumentar o número de espigas por metro quadrado; porém, o aumento das doses de $\mathrm{N}$ pode causar a redução da massa de 100 grãos e da massa hectolítrica.

4. O incremento na dose de nitrogênio até a aplicação de $120 \mathrm{~kg} \mathrm{ha}^{-1}$ aumenta a produtividade de grãos de trigo irrigado, independentemente da época de aplicação e da fonte de nitrogênio.

\section{Agradecimentos}

À Coordenação de Aperfeiçoamento de Pessoal de Nível Superior e ao Conselho Nacional de Desenvolvimento Científico e Tecnológico, por concessão de bolsas; e à Fundação de Amparo à Pesquisa do Estado de São Paulo, pelo apoio financeiro.

\section{Referências}

BREDEMEIER, C.; MUNDSTOCK, C.M. Estádios fenológicos do trigo para a adubação nitrogenada em cobertura. Revista Brasileira de Ciência do Solo, v.25, p.317-323, 2001.

CANTARELLA, H.; RAIJ, B. van; CAMARGO, C.E.O. Cereais. In: RAIJ, B. van; CANTARELLA, H.; QUAGGIO, J.A.; FURLANI, A.M.C. Recomendações de adubação e calagem para o Estado de São Paulo. Campinas: IAC, 1997. 285p. (IAC. Boletim técnico, 100).

CHAPMAN, S.C.; BARRETO, H.J. Using a chlorophyll meter to estimate specific leaf nitrogen of tropical maize during vegetative growth. Agronomy Journal, v.89, p.557-562, 1997.

COELHO, M.A.O.; SOUZA, M.A.; SEDIYAMA, T.; RIBEIRO, A.C.; SEDIYAMA, C.S. Resposta da produtividade de grãos e outras características agronômicas do trigo Embrapa-22 irrigado ao 
nitrogênio em cobertura. Revista Brasileira de Ciência do Solo, v.22, p.555-561, 1998.

FOLLETT, R.H.; FOLLETT, R.F.; HALVORSON, A.D. Use of a chlorophyll meter to evaluate the nitrogen status of dryland winter wheat. Communications in Soil Science and Plant Analysis, v.23, p.687-697, 1992.

FRANK, A.B.; BAUER, A. Temperature, nitrogen and carbon dioxide effects on spring wheat development and spikelet numbers. Crop Science, v.36, p.659-665, 1996.

FURLANI, A.M.C.; GUERREIRO FILHO, O.; COELHO, R.M.; BETTI, J.A.; FREITAS, S.S. Recomendações da comissão técnica de trigo para 2002. 3.ed. Campinas: Instituto Agronômico, 2002. 92p. (Série tecnológica APTA. Boletim técnico IAC, 167).

KLUTHCOUSKI, J.; AIDAR, H.; THUNG, M.; OLIVEIRA, F.R. de A. Manejo antecipado do nitrogênio nas principais culturas anuais. Santo Antônio de Goiás: Embrapa Arroz e Feijão, 2006. 64p. (Embrapa Arroz e Feijão. Documentos, 188).

LOPEZ-BELLIDO, R.J.; SHEPHERD, C.E.; BARRACLOUGH, P.B. Predicting post-anthesis N requirements of bread wheat with a Minolta SPAD meter. European Journal of Agronomy, v.20, p.313-320, 2004.

LOS FERTILIZANTES y su uso: una guía de bolsillo para los oficiales de extensión. 4.ed. Roma: FAO: IFA, 2002. 87p. Disponível em: <www.fertilizer.org>. Acesso em: 05 set. 2006.

LOURENTE, E.R.P.; ONTOCELLI, R.; SOUZA, L.C.F. de; GONÇALVES, M.C.; MARCHETTI, M.E.; RODRIGUES, E.T. Culturas antecessoras, doses e fontes de nitrogênio nos componentes de produção do milho. Acta Scientiarum. Agronomy, v.29, p.55-61, 2007.

MEGDA, M.M.; BUZETTI, S.; ANDREOTTI, M.; TEIXEIRA FILHO, M.M.C.; VIEIRA, M.X. Resposta de cultivares de trigo ao nitrogênio em relação às fontes e épocas de aplicação sob plantio direto e irrigação por aspersão. Ciência e Agrotecnologia, v.33, p.1055-1060, 2009.

OKUYAMA, L.A.; FEDERIZZI, L.C.; BARBOSA NETO, J.F. Correlation and path analysis of yield and its components and plant traits in wheat. Ciência Rural, v.34, p.1701-1708, 2004.

PENCKOWSKI, L.H. Efeitos de trinexapac-ethyl e do nitrogênio na produtividade da cultura de trigo. 2006. 84p. Dissertação (Mestrado) - Universidade Estadual de Ponta Grossa, Ponta Grossa.

PERUZZO, G.; SIQUEIRA, O.J.F. de; WIETHÖLTER, S. Eficiência agronômica de fertilizantes nitrogenados para a cultura do trigo. Pesquisa Agropecuária Brasileira, v.29, p.1027-1034, 1994.

PIEKIELEK, W.P.; FOX, R.H. Use of a chlorophyll meter to predict sidedress nitrogen requirements for maize. Agronomy Journal, v.84, p.59-65, 1992.

POTTKER, D.; FABRÍCIO, A.C.; NAKAYAMA, L.H.I. Doses e métodos de aplicação de nitrogênio para a cultura do trigo. Pesquisa Agropecuária Brasileira, v.19, p.1197-1201, 1984.

POVH, F.P.; MOLIN, J.P.; GIMENEZ, L.M.; PAULETTI, V.; MOLIN, R.; SALVI, J.V. Comportamento do NDVI obtido por sensor ótico ativo em cereais. Pesquisa Agropecuária Brasileira, v.43, p.1075-1083, 2008.

RAIJ, B. van; QUAGGIO, J.A. Métodos de análise de solo para fins de fertilidade. Campinas: IAC, 1983. 31p. (IAC. Boletim técnico, 81).

REUNIÃO DA COMISSÃO CENTRO BRASILEIRA DE PESQUISA DE TRIGO, 13., 2004, Goiânia. Informações técnicas para a cultura de trigo na região do Brasil Central: safras 2005 e 2006. Santo Antônio de Goiás: Embrapa arroz e feijão, 2005. 86p. (Embrapa Arroz e Feijão. Documentos, 173).

ROS, C.O. da; SALET R.L.; PORN, R.L.; MACHADO, J.N.C. Disponibilidade de nitrogênio e produtividade de milho e trigo com diferentes métodos de adubação nitrogenada no sistema plantio direto. Ciência Rural, v.33, p.799-804, 2003.

SANGOI, L.; BERNS, A.C.; ALMEIDA, M.L. de; ZANIN, C.G.; SCHWEITZER, C. Características agronômicas de cultivares de trigo em resposta à época da adubação nitrogenada de cobertura. Ciência Rural, v.37, p.1564-1570, 2007.

SANTOS, H.G. dos; JACOMINE, P.K.T.; ANJOS, L.H.C. dos; OLIVEIRA, V.A. de; OLIVEIRA, J.B. de; COELHO, M.R.; LUMBRERAS, J.F.; CUNHA, T.J.F. (Ed.). Sistema brasileiro de classificação de solos. 2.ed. Rio de Janeiro: Embrapa Solos, 2006. $306 \mathrm{p}$.

SILVA, D.B. Efeito do nitrogênio em cobertura sobre o trigo irrigado em sucessão à soja na região dos Cerrados. Pesquisa Agropecuária Brasileira, v.26, p.1387-1392, 1991.

SILVA, S.A. da; ARF, O.; BUZETTI, S.; SILVA, M.G. da. Fontes e épocas de aplicação de nitrogênio em trigo em sistema plantio direto no Cerrado. Revista Brasileira de Ciência do Solo, v.32, p.2717-2722, 2008.

TEIXEIRA FILHO, M.C.M.; BUZETTI, S.; ALVAREZ, R. de C.F.; FREITAS, J.G. de; ARF, O.; SÁ, M.E. de. Desempenho agronômico de cultivares de trigo em resposta a população de plantas e a adubação nitrogenada. Científica, v.36, p.97-106, 2008.

TEIXEIRA FILHO, M.C.M.; BUZETTI, S.; ALVAREZ, R. de C.F.; FREITAS, J.G. de; ARF, O.; SÁ, M.E. de. Resposta de cultivares de trigo irrigado por aspersão ao nitrogênio em cobertura na Região do Cerrado. Acta Scientiarum. Agronomy, v.29, p.421-425, 2007.

TRINDADE, M. da G.; STONE, L.F.; HEINEMANN, A.B.; CÁNOVAS, A.D.; MOREIRA, J.A.A. Nitrogênio e água como fatores de produtividade do trigo no Cerrado. Revista Brasileira de Engenharia Agrícola e Ambiental, v.10, p.24-29, 2006.

YANO, G.T.; TAKAHASHI, H.W.; WATANABE. T.S. Avaliação de fontes de nitrogênio e épocas de aplicação em cobertura para o cultivo do trigo. Semina. Ciências Biológicas e da Saúde, v.26, p.141-148, 2005.

ZAGONEL, J.; VENÂNCIO, W.S.; KUNZ, R.P.; TANAMATI, H. Doses de nitrogênio e densidade de plantas com e sem um regulador de crescimento afetando o trigo, cultivar OR-1. Ciência Rural, v.32, p.25-29, 2002.

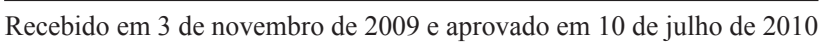

